\title{
Research on load bearing performance recovery method of a RC simply-supported beam bridge
}

\author{
Dejun Mao ${ }^{1, *}$, Zongxing Zhang ${ }^{2}$, Xun Jiang ${ }^{3}$, Liu Jinlin ${ }^{4}$, Lan Shuwei ${ }^{1}$ \\ ${ }^{1}$ College of Architecture and Civil Engineering, Kunming University, Kunming 650214, China \\ ${ }^{2}$ Kunming Municipal Engineering Design \& Science Research Institute Co.,Ltd , Kunming 650228, China \\ ${ }^{3}$ Yunnan Communications Investment Group Highway Construction Co., Ltd., Kunming 650034, China \\ ${ }^{4}$ Zhaotong Expressway Construction and Maintenance Engineering Co., Ltd, Zhaotong 657000, China
}

\begin{abstract}
The load-bearing performance of a RC simply supported beam bridge was comprehensively detected and evaluated. The appearance detection results show that there is a large area of damaged and exposed reinforcement in the main girder and diaphragm plate of the bridge. The detecting results of material condition and state parameters show that the durability of the bridge is insufficient, the risk of steel corrosion is large, and the strength condition of concrete material is poor. The load test results show that the bearing capacity of the bridge does not meet the requirements. In view of the current situation of the bridge, a comprehensive reinforcement treatment scheme was proposed, in which modified epoxy mortar is used to repair the main beam and diaphragm of the whole bridge, steel plate is pasted to reinforce the main beam of the whole bridge, and anticorrosive coating is applied on the main beam and diaphragm.
\end{abstract}

\section{Introduction}

In actual engineering, due to various reasons, such as longterm use of functional degradation, earthquakes and other natural disasters, changes in structural use functions, improper design, poor construction quality, the bridge's bearing capacity is insufficient, safety and reliability are reduced, and reinforcements are needed. Reinforced concrete (RC) simply supported beam bridges have the characteristics of simple force, convenient design and calculation, and low construction cost, and have been widely used worldwide. This article takes an RC simply supported beam bridge as the background, and according to the detailed inspection and evaluation results of the bridge, a comprehensive reinforcement treatment plan was formulated to repair the main girder and diaphragm of the full bridge with modified epoxy mortar, reinforce the main girder of the bridge with glued steel plates, and apply anticorrosive coating to the main girder and diaphragm of the entire bridge, so as to restore and improve the bearing performance of the bridge. The reinforcement treatment plan in this article can provide reference for similar bridge treatment.

\section{Project profile}

An RC simply supported beam bridge in Guangdong Province, China, was built in 2002 with a span of $1 \times 13.0 \mathrm{~m}$. The full bridge consists of two left and right parallels, each with a width of $10.2 \mathrm{~m}$, and the total width of the bridge is $20.4 \mathrm{~m}$. Both the left and right parallels are arranged with 6 pieces of reinforced concrete simply supported T beams, 4 transverse partitions are arranged at equal intervals along the longitudinal direction of the $\mathrm{T}$ beams, the support is plate rubber bearing, the abutment is gravity abutment, and the deck pavement for asphalt concrete. The design load is car -20 class, trailer -100 , and crowd load is $3.5 \mathrm{kN} / \mathrm{m}^{2}$. The cross-section layout of the bridge is shown in Figure 1, and the cross-section size of the main beam is shown in Figure 2.

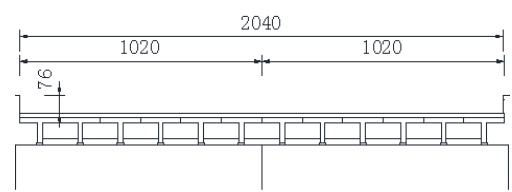

Figure 1. Cross-section layout of the bridge (Unit: $\mathrm{cm}$ ).

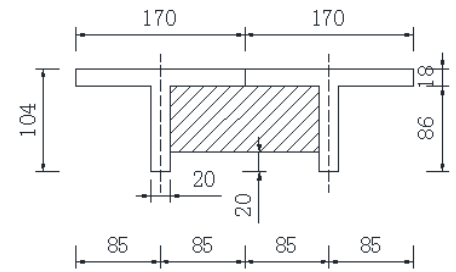

Figure 2. Cross-section size of the main beam (Unit: $\mathrm{cm})$. 


\section{Bridge detection results}

\subsection{Appearance detection}

According to the method of the Chinese standard "Specification for Inspection and Evaluation of Loadbearing Capacity of Highway Bridges" JTG/T J21-2011, the bridge has been visually detected. The main results are as follows:

- Bridge deck system: There are 2 traces of transverse crack repair on the bridge deck, which are good after repair; 1 trace of longitudinal crack repair, which cracks after repair; there is 1 loose and dislocation of the curb in the green belt on the right.

- Superstructure: The main beams and diaphragms of the full bridge have large areas of damaged and exposed bars. The exposed bars of some main beams and diaphragms are shown in Figures 3 to 4; the overall condition of the full bridge supports is good.

- substructure: The abutment is slightly scoured with pockmarked surface and attached with oil.

- Underwater foundation: There is no erosion of the foundation.

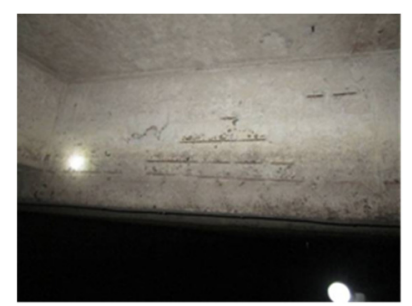

Figure 3. Exposed reinforcement of main girder.

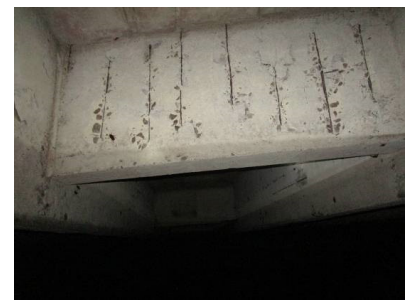

Figure 4. Exposed reinforcement of diaphragm plate.

The appearance detection results show that the main diseases of the bridge are: the main girder and the diaphragm have large areas of damaged and exposed bars. The reason is that the thickness of the concrete protective layer is insufficient, and the corrosion and expansion of the steel bars cause the protective layer to peel off.

\subsection{Material condition and state parameter detection}

According to the method of the Chinese standard " Standards for Technical Condition Evaluation of Highway Bridges" JTG/T H21-2011, the material condition and state parameters of the bridge were detected and evaluated. The main results are as follows:

- The test results of steel corrosion potential show that the lowest value of steel corrosion potential of each test component is $(-300,-400] \mathrm{mV}$, which indicates that the bridge has corrosion activity and the probability of corrosion is greater than $90 \%$. The evaluation scale is 3 .

- The concrete resistivity test results show that: the resistivity of each test member is $10000 \leq \rho<15000$, and the possible corrosion rate of the steel bar is general, and the evaluation scale is 3 .

- The test results of the thickness of the steel bar protection layer show that the thickness of the steel bar protection layer $D_{n e} / D_{n d}$ of each test component is less than or equal to 0.55 , the thickness of the steel bar protection layer is poorly controlled, and the steel bars are easy to lose alkaline protection and rust. The evaluation scale is 5 .

- The test results of concrete carbonation depth show that the concrete carbonation depth $\mathrm{Kc}$ of each test member is less than 0.5 , which has a small effect on the corrosion of steel bars, and the evaluation scale is 1 .

- The test results of concrete strength show that the concrete strength of each test member is $0.80 \leq \mathrm{K}_{\mathrm{bt}}<$ 0.90 , and the overall strength of the bridge material is poor, and the evaluation scale is 3 .

- The test results of the chloride ion content show that the chloride ion content of each test component (percentage of the cement content) $0.40 \leq \S<0.70$, may induce corrosion of steel bars. The evaluation scale is 3 .

The detecting results of material conditions and state parameters show that the bridge has insufficient durability, high risk of steel corrosion, and poor strength of concrete materials. The reason is that the location of the bridge is in a typical atmospheric ocean climate environment, with high ambient temperature, high air humidity, and high content of corrosive ions in the air. The construction quality of the concrete was not well controlled during the construction of the bridge.

\subsection{Load test}

According to the method of the Chinese standard " Load Test Methods for Highway Bridge" JTG/T J21-01-2015, the static load test and dynamic load test were carried out on the bridge, and the main results are as follows:

- Static load test: The strain and deflection calibration coefficients of the key measuring points in the left and right parallels main beams are greater than 1 , indicating that the bearing capacity does not meet the requirements; the relative residual deformation of the beam after unloading is less than $20 \%$.

- Dynamic load test: The measured pulsation, sports car, brake, and car jump fundamental frequencies of the left and right parallels main beams are all greater than the theoretically calculated values.

The load test results show that the load-bearing capacity of the bridge does not meet the requirements due to the large-area damage of the main girder and the diaphragm plate, the exposed reinforcement, the corrosion of the steel bar, and the poor concrete strength. 


\section{Treatment plan}

The bearing capacity of the bridge does not meet the requirements of use, and it should be repaired and reinforced. According to the disease condition of the bridge, the following comprehensive reinforcement treatment plan has been formulated.

\subsection{Repair damage and exposed reinforcement}

Use modified epoxy mortar to repair the damaged and exposed steel reinforcement of the main girder and diaphragm plate of the full bridge. The repair process is shown in Figure 5.

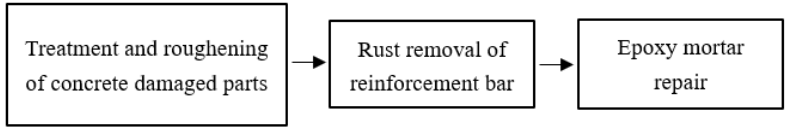

Figure 5. Repair process.

The purpose of processing and chipping the damaged concrete is to clean the loose part thoroughly and to make the concrete surface have a certain degree of roughness. During the construction process, it is forbidden to use equipment with high impact force. Manual methods can be used to ensure that the steel bars and adjacent concrete are not damaged. After the treatment is completed, compressed air is used to remove dust. When the concrete base surface is wet, the moisture fills the cracks, causing the epoxy mortar slurry to not penetrate into the concrete matrix, which will significantly reduce the bonding effect [1]. Therefore, the concrete surface should be kept dry during the treatment process, and it is strictly forbidden to wash it with water.

After concrete treatment and chiseling, the steel bars should be derusted. After the steel bar is derusted, apply rust inhibitor on its surface. The rust inhibitor can improve the passive film on the surface of the steel bar, improve the anti-corrosion ability of the passive film, and thus increase the service life of the reinforced concrete structure. According to different classification methods, steel bar rust inhibitors can be divided into organic rust inhibitors, inorganic rust inhibitors, blended rust inhibitors, migration type rust inhibitors, etc. [2]. There are many kinds of steel bar rust inhibitors on the market, and the effect is uneven [3]. The RI-1 series of rust inhibitors are the earliest developed and most widely used products. For example, RI-1C2 type steel bar rust inhibitors are used in Guangdong Foshan Expressway Bridge, Yuehai Railway Hub Overpass, and Hangzhou Bay Bridge [4]. RI-1C2 type rust inhibitor is proposed to be used for the protection of the bridge steel bars.

Before repairing with epoxy mortar, a layer of modified epoxy-based liquid should be applied to the surface of the concrete to keep the concrete moist to ensure reliable bonding between the epoxy mortar and the concrete. Epoxy mortar is made of ordinary cement mortar and epoxy resin modified materials according to a certain proportion. The amount of epoxy resin, curing agent, polymer cement ratio, polymer sand ratio and aggregate gradation have obvious effects on its strength and bonding performance. The epoxy mortar mix ratio used in the bridge is: epoxy resin: thinner: curing agent mass ratio $10: 4: 3$, polymer-cement ratio is 1.5 , and polymer-sand ratio is 1:6. Studies have shown that the epoxy mortar material with this ratio has high strength and good bonding performance [5].

\subsection{Bonding steel plate reinforcement}

The main girders of the whole bridge are reinforced with glued steel plates to restore and improve its bearing capacity. The reinforcement scheme is designed as follows:

A $5 \mathrm{~mm}$ thick, $18 \mathrm{~cm}$ wide Q345qE steel plate strip is pasted along the bottom of each main beam within $6 \mathrm{~m}$ on both sides of the middle span; U-shaped hoop plates are added to strengthen the anchorage and improve the end shear capacity, and the main beam is glued to steel the reinforcement design is shown in Figure 6, and the specifications and dimensions of the steel plates required for the reinforcement of each main beam are shown in Table 1. Before sticking the steel plate, chemically inject the cracks with a width greater than $0.15 \mathrm{~mm}$.

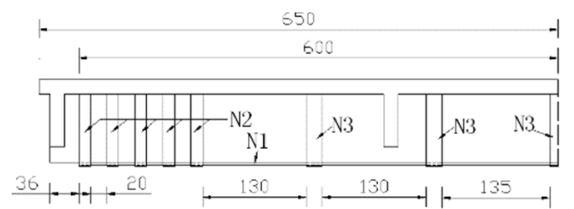

Figure 6. Main beam reinforcement design drawing (Unit: $\mathrm{cm})$.

Table1. Specification and size of steel plate required for reinforcement of main beam.

\begin{tabular}{|c|c|c|c|c|}
\hline $\begin{array}{c}\text { Type } \\
\text { number }\end{array}$ & $\begin{array}{c}\text { Length } \\
/ \mathrm{cm}\end{array}$ & $\begin{array}{c}\text { Width } \\
/ \mathrm{cm}\end{array}$ & $\begin{array}{c}\text { Thickness } \\
/ \mathrm{mm}\end{array}$ & Quantity \\
\hline $\mathrm{N} 1$ & 1200 & 20 & 5 & 1 \\
\hline $\mathrm{N} 2$ & 190 & 15 & 5 & 10 \\
\hline $\mathrm{N} 3$ & 190 & 20 & 5 & 5 \\
\hline
\end{tabular}

The construction process of sticking steel plate reinforcement is shown in Figure 7.

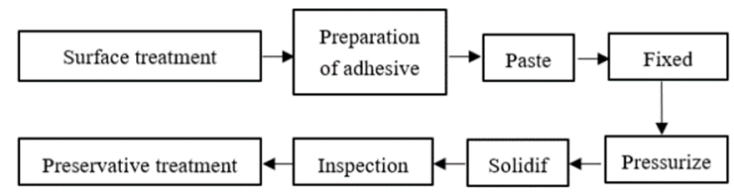

Figure 7. Construction process of sticking steel plate reinforcement.

The construction should be carried out by a skilled construction team to strictly control the construction quality. The method of sticking with steel plate reinforcement should be unloaded as much as possible. Considering that the bridge is located in an urban area, where the flow of people and vehicles is intensive, it is impossible to completely close the traffic, so the framing reinforcement is adopted. 


\subsection{To coat anti-corrosion coating}

The main beam and diaphragm of the whole bridge are coated with anti-corrosion coating to solve the problems of steel corrosion and insufficient durability. The anticorrosion coating construction shall be carried out after the steel plate is pasted. A large number of engineering practices have shown that coating anticorrosive coatings on RC bridge structures can effectively block the corrosive ion erosion in the atmosphere, delay the corrosion of steel bars, and carbonization and cracking of component concrete [6]. At present, anti-corrosion coatings have been widely used in bridge engineering, especially for rivercrossing and river-crossing bridges in offshore areas [7].

Considering the environmental temperature, humidity and other factors of the bridge, the material of anticorrosion coating is selected, and E26 anti-corrosion coating material which can effectively resist external factors and invasion erosion and meet the requirements of relevant standards is adopted [8]. The material information of E26 anti-corrosion coating is shown in Table 2, and its performance can meet the anti-corrosion requirements of the bridge. The anti-corrosion coating construction includes three layers, namely bottom layer, middle layer and surface layer.

Table2. E26 anti-corrosion coating material information.

\begin{tabular}{|c|c|c|c|}
\hline $\begin{array}{l}\text { Coating } \\
\text { name }\end{array}$ & Coatings & Materials & $\begin{array}{l}\text { Mechanism } \\
\text { of action }\end{array}$ \\
\hline \multirow{3}{*}{ E26 } & Bottom layer & $\begin{array}{l}\text { H06-10 } \\
\text { primers }\end{array}$ & $\begin{array}{l}\text { Infiltration } \\
\text { into concrete }\end{array}$ \\
\hline & $\begin{array}{l}\text { Intermediate } \\
\text { layer }\end{array}$ & H45-ZF101 & $\begin{array}{c}\text { Film forming } \\
\text { on concrete } \\
\text { surface }\end{array}$ \\
\hline & Surface & $\begin{array}{l}\text { PV-50 } \\
\text { topcoat }\end{array}$ & $\begin{array}{c}\text { Film forming } \\
\text { on concrete } \\
\text { surface }\end{array}$ \\
\hline
\end{tabular}

\section{5 concluding remarks}

This article takes an RC simply supported beam bridge as the background, the bearing capacity of the bridge is comprehensively evaluated by bridge appearance inspection, bridge material condition inspection and state parameter inspection, static load test and dynamic load test. According to the results of bearing capacity evaluation, a comprehensive reinforcement treatment plan was formulated to repair the main girder and diaphragm of the full bridge with modified epoxy mortar, reinforce the main girder of the bridge with glued steel plates, and apply anticorrosive coating to the main girder and diaphragm of the entire bridge, so as to restore and improve the bearing performance of the bridge. The reinforcement treatment plan in this article can provide reference for similar bridge treatment.

\section{Acknowledgments}

Authors wishing to acknowledge assistance from the Youth Project of the Joint Special Fund for Basic Research of Local colleges and universities in Yunnan Province (2019FH001(-100)).

\section{References}

1. Fang Liu, Lingling $\mathrm{Xu}$, Mingshu Tang. Effects of interfacial roughness and wetness on repair effectiveness of epoxy resin based repairing mortar. Journal of Nanjing University of Technology (Natural Science Edition), 35: 36-41, (2013)

2. Yinbo Gao, Juan Hu, Qing Liu, et al. Applications and prospects of corrosion inhibitors for reinforcing steel. Journal of Xiamen University (Natural Science), 54: 713-720, (2015)

3. Xiaotong Wang, Congtao Sun, Qing Liu, et al. Inhibition mechanism of amino alcohol corrosion inhibitors. Bulletin of the Chinese Ceramic Society, 36: 84-88, (2017)

4. Naifeng Hong. Development and use of steel bar inhibitor. Industrial Construction, 35: 68-70+79, (2005)

5. Chanchan Li, Dejin Cheng, Cheng Lian, et al. Study of factors influencing on epoxy mortar strength. Adhesion, 37: 58-60+75, (2016)

6. Yaoqing Wen, Wenchun Wen, Zuxin Sun. The anticorrosive maintenance painting program for surface of anchored reinforced concrete structure of Haicang Bridge in Xiamen. Shanghai Coatings, 54: 49-51, (2016)

7. Sike Shen, Shuya Bai, Yunsheng Tian, et al. Discussion on the use of industrial protection coatings in bridge engineering. China Coatings, 25: 55-58, (2010)

8. Ming Ji, Yueliang Gan, Chaohai Ding, et al. Application of high performance concrete and coating of protective paint on a port in Zhejiang province. Journal of Civil and Environmental Engineering, 37: 23-27, (2015) 